Research Article

\title{
EFFECT OF GENOTYPE AND CULTURE MEDIA ON CALLUS INDUCTION AND PLANT REGENERATION FROM MATURED RICE GRAIN CULTURE
}

\author{
R. K. Niroula, B. P. Sah, H. P. Bimb and S. Nayak \\ Nepal Agricultural Research Council, Khumaltar, Lalitpur, Nepal \\ e-mail: rkn27st@yahoo.com
}

\begin{abstract}
This study was under taken to elucidate the effect of genotypes and media compositions on callus induction from mature rice seeds. Three different callus induction media, designated as A (N6 mineral salts $+\mathrm{N} 6$ vitamins, $2 \mathrm{mg} / \mathrm{l}$ each + myoinositol, $100 \mathrm{mg} / \mathrm{l}+$ 2,4-D, $2.5 \mathrm{mg} / 1+$ kinetin, $0.5 \mathrm{mg} / 1+\mathrm{AgNO}, 10 \mathrm{mg} / 1+$ maltose, $50 \mathrm{gm} / \mathrm{l}$ ); B (MS organic salts $+\mathrm{N} 6$ mineral salts $+\mathrm{NAA}, 4 \mathrm{mg} / 1+$ kinetin, $2 \mathrm{mg} / 1+\mathrm{AgNO}$, $5 \mathrm{mg} / 1$ and sucrose, $60 \mathrm{gm} / \mathrm{l})$; and $\mathrm{C}\left(\mathrm{B}\right.$ media without $\mathrm{AgNO}_{3}$ ), and six rice genotypes viz. Jumlimarshi, Tilki, Jethobudo, Manshara, Masuli and Pahenle were evaluated. The modified N6 medium supplemented with 2, 4-D, $2.5 \mathrm{mg} / 1$ and $\mathrm{AgNO}_{3}, 10 \mathrm{mg} / \mathrm{l}$ exhibited better performance in callus induction. Among genotypes, callus induction frequency was higher $(100 \%)$ in Masuli, Tilki and Jumlimarshi regardless of media tested. The positive effect of $\mathrm{AgNO}_{3}$ was only observed in medium A for quality callus induction and subsequent plant regeneration. The genotype Tilki performed better regarding plant regeneration $(27.77 \%)$. Therefore, it is suggested that application of medium A is advantageous to accomplish overall efficiency of callus induction and plant regeneration from seeds of various rice genotypes.
\end{abstract}

Key words: 2, 4-D, $\mathrm{AgNO}_{3}$, dehulled rice, in vitro, regeneration

\section{IN'TRODUCTION}

Rice (Oryza sativa L.) is one of the most important cereal crops, which supplies food for more than half of the world's population ('Tyagi et al., 2004). A considerable improvement has already been made by exploiting the natural variation through conventional breeding. Albeit the success made in the last century, traditional breeding efforts alone can not meet the increasing demand of rice consumers in the $21^{\text {st }}$ century. Therefore, at present various tissue culture techniques are being used for the genetic improvement of rice plant throughout the world (Raina, 1989). Among techniques, anther culture, protoplast fusion and culture, leaf culture, root culture, immature embryo culture and mature seed culture are important in rice to create additional variation and novel rice varieties (Lutts et al., 2001; Sathish et al., 1995). It has been demonstrated in several cases that when higher plant tissues undergo a process of dedifferentiation and cell proliferation in vitro, wide range of mutations occur at a frequency much higher than expected (Brar and Khush, 1994). Somaclones provide a novel and valuable source of genetic variability, which can be exploited for crop improvement particularly, for the development of stress tolerance rice cultivars (Lutts et al., 1999).

In the most agronomically important crop species, somaclonal variation is greater than that of variation displayed among the seed progeny of the donor (Skirvin, 1978). Several high yielding rice varieties were developed through the application of anther culture, and other forms of somaclones in rice (Lutts et al., 2001, Gupta, 1999, Sathish et al., 1995, Raina, 1989). However, plant regeneration from callus obtained from somatic tissue is more successful than that of anther culture (Guo and Cao, 1982). Hartke and Lorz (1989) tested 15 indica rice lines and found that seven of them produced embryogenic calli and only four regenerated into plants. Abe and Fustsuhara (1986) tested 66 indica and japonica cultivars and reported that japonica varieties exhibited a higher rate of callus induction and regeneration than those of indica. Moreover, many agronomically valuable rice genotypes are recalcitrant to in vitro manipulation because of their poor callus production and regeneration ability. High frequency of callus induction and green plant regeneration is a perquisite for utilization of indica rice somaclones in breeding programmes. In this context, the evaluation of new factors and their manipulation for efficient callusing and green plant regeneration from dehulled seeds in indica rice is still challenging field. 
Dehulled grain culture (embryo) being the most popular and easily accessible materials among wide ranges of tissue to be used as explants for rice tissue culture (Raina, 1989). Many experiments have been conducted to optimize the techniques and composition of culture medium for callus induction from dehulled rice seed for various purposes (Islam et al., 2004, Khatun et al., 2003, Wang et al., 1987). However, its application is still limited by many factors influencing the culture efficiency such as medium composition (Sun and Zheng, 1990), explants source (Torbert et al., 1998), genotype (Shen et al., 1982) and environment (Qu and Chen, 1983). Among them the genotype and nutrient composition are regarded to be the major sources of variation in in vitro culture (Khanna and Raina, 1998). In the backcloth of the above situations, the present study was carried out to compare the performance of six dehulled rice varieties in respect of their callusing ability in three different cultural media with various supplements.

\section{MATERIAL AND METHODS}

This study was conducted during the winter season of 2005 at biotechnology laboratory of Biotechnology Unit, Nepal Agriculture Research Council (NARC), Khumaltar, Nepal. Dehulled mature seeds from six rice genotypes, viz. Jumlimarshi, Tilki, Jethobudo, Manshara, Masuli, and Pahenle covering diverse ecology of Nepal were used in this study. These genotypes were kindly provided by Plant Genetic Resource Unit of Agri-Botany Division, NARC. Seeds from each genotype were dehulled manually, washed in distilled water and dipped in $70 \%$ ethanol for 1 minute. The seeds were then dipped in a $0.1 \mathrm{HgCl}_{2}$ for 20 minutes, washed for three to four times with sterilized doubled distilled water and finally dried with sterilized filter paper. The finally dried sterilized seeds were then inoculated in three different callus induction media designated as A, B and C. These media were prepared by supplying the following ingredients: Medium (A): N6 mineral salts (Chu, 1978) + N6 vitamins, $2 \mathrm{mg} / \mathrm{l} \mathrm{each}+$ myoinositol, $100 \mathrm{mg} / 1+2,4-\mathrm{D}, 2.5 \mathrm{mg} / \mathrm{l}+$ kinetin, $0.5 \mathrm{mg} / 1+\mathrm{AgNO}_{3}, 10 \mathrm{mg} / \mathrm{l}+$ maltose, 50 $\mathrm{gm} / \mathrm{l}$, medium (B): MS organic salts (Murashige and Skoog, 1962) + N6 mineral salts + NAA, $4 \mathrm{mg} / \mathrm{l}+$ kinetin $2 \mathrm{mg} / \mathrm{l}+\mathrm{AgNO}_{3}, 5 \mathrm{mg} / \mathrm{l}$ and sucrose, $60 \mathrm{gm} / 1$, and medium C: B medium without $\mathrm{AgNO}_{3}$.

Half MS medium supplemented with sucrose $20 \mathrm{gm} / 1$, NAA $1 \mathrm{mg} / \mathrm{l}$, BAP $2 \mathrm{mg} / \mathrm{l}$, Kinetin 0.5mg/l was used for regeneration of the seed derived calli. The $\mathrm{pH}$ of each medium was adjusted at 5.8 by adding $\mathrm{NaOH}$ $(0.1 \mathrm{~N})$ prior to adding gelling agent, agar. All the media were solidified with $0.7 \%$ agar. Conical flasks with respective medium were sterilized by autoclaving at 15 psi for 18 minutes. Once the media were completely sterilized, flasks containing media were allowed to cool to $55^{\circ} \mathrm{C}$. The cooled media were then dispensed @ 20 $\mathrm{ml}$ per $70 \mathrm{~mm}$ petriplates. Seven seeds per plate were maintained in each replication. Replications were varied from 3-4 depending on the availability of seeds. The cultured petriplates were sealed using parafilim and incubated at $25 \pm 1^{\circ} \mathrm{C}$ in total darkness for 25 days. The first observation was recorded at 10 days after caryopsis inoculation and then repeated twice at five days interval. All experiments were done following completely randomized design (CRD) with unequal replications. The seed derived 27 days old calli were isolated and cultured in the regeneration medium for ten days at 16 hours photoperiod at $\sim 3000$ lux and $25^{\circ} \pm 10^{\circ} \mathrm{C}$. Calli were then further transferred to the same regeneration medium and the cultures maintained as earlier. After two months of incubation in regeneration medium, the well rooted plants were transferred onto plastic pots and hardened following the method of Niroula et al. (2003). Finally hardened seedlings were further transferred into plastic bucket containing fertilized puddle soil and grown in glasshouse.

Callus induction frequency was recorded considering that each callus piece originated from a single seed. The frequency of callus induction and regeneration was calculated as follows: Callus induction frequency $(\%)=$ number of grains producing calli/number of grains plated x 100 and regeneration frequency $(\%)=$ number of plants recovered/number of calli plated $\mathrm{x} 100$. The percent value was transformed into arcsine $\sqrt{\mathrm{x}}$ function (Gomez and Gomez, 1984) and analyzed by standard statistical computer package (MINITAB version 10). Means of each treatment were separated by Duncan's Multiple Range Test (DMRT) using MSTATC.

\section{RESULTS AND DISCUSSION}

Dehulled seeds from six rice genotypes were tested to study their callus forming ability using three different media. From this study it was found that the genotypes, media compositions and their interactions significantly affected the callus induction at 1\% level. Most of the responsive genotypes in respective media developed calli 
within 10 days of inoculation (Figures 1 and 2). The rate of callus induction was similar in B and C media (Table 1) however, calli obtained from $B$ medium were quite good in texture and friable in nature than that of $C$. Maximum callus $(100 \%)$ was observed for genotypes Masuli in medium B, and Tilki and Jumlimarshi in medium A. Low frequency of callus was observed for Jumlimarshi in medium B, that was significantly different from the rest of the media tested.

Mean frequency of callus induction over media (Table 1) showed that the genotype Masuli produced maximum callus $(88.20 \%$ ) which was significantly higher than the rest of the genotypes except Tilki $(79.65 \%)$ and Jethobudo (76.64\%). Among the media composition, medium A was found to be most effective for callus induction (84.34\%). Although some genotypes performed better in media B and C, the quality of calli was not as good as those induced in medium A. Most of the calli surface induced from media B and C was covered with profuse roots. The observations found in this study are in agreement with the findings of other researchers (Islam et al., 2004, Khatun et al., 2003, Pandey et al., 1994). They reported that the success of in vitro cultures largely depend on the use of harmonious combinations of nutritional constituents and growth regulators.

Table 1. Interaction between the genotypes and cultural media on callus induction of six rice genotypes

\begin{tabular}{|lllll|}
\hline \multirow{2}{*}{ Genotypes } & \multicolumn{3}{c|}{ Mean arcsine value of callus induction (original frequency \%) } \\
\cline { 2 - 4 } & \multicolumn{3}{c|}{ Media } & Mean over media \\
\cline { 2 - 4 } & A & B & C & $55.87 \mathrm{~d}$ \\
Jumlimarshi & $88.92 \mathrm{a}$ & $31.56 \mathrm{~d}$ & $(53.5)$ & $(62.83)$ \\
Tilki & $(100.00)$ & $(35.49)$ & $55.54 \mathrm{bc}$ & $70.83 \mathrm{ab}$ \\
& 88.92 & $68.02 \mathrm{bc}$ & $(67.50)$ & $(79.65)$ \\
Jethobudo & $(100.00)$ & $(82.00)$ & $60.60 \mathrm{bc}$ & $68.15 \mathrm{ab}$ \\
& $75.83 \mathrm{ab}$ & $68.02 \mathrm{bc}$ & $(75.00)$ & $(76.64)$ \\
Manshara & $(89.25)$ & $(82.00)$ & $58.20 \mathrm{bc}$ & $(70.54)$ \\
Masuli & $58.82 \mathrm{bc}$ & $71.16 \mathrm{ab}$ & $78.43 \mathrm{a}$ \\
& $(71.67)$ & $(82.0)$ & $70.53 \mathrm{ab}$ & $(88.20)$ \\
Pahenle & $75.83 \mathrm{ab}$ & $88.92 \mathrm{a}$ & $(85.75)$ & $55.47 \mathrm{~cd}$ \\
& $(89.25)$ & $(100.00)$ & $55.54 \mathrm{bc}$ & $(62.38)$ \\
Mean over & $61.68 \mathrm{bc}$ & $49.20 \mathrm{~cd}$ & $(67.5)$ & 65.25 \\
genotype & $(71.50)$ & $(57.0)$ & $57.93 \mathrm{~b}$ & $* *$ \\
P-value & $75 \mathrm{a}$ & $62.81 \mathrm{~b}$ & $(65.15)$ & 19.13 \\
CV (\%) & $(84.34)$ & $(62.81)$ & $* *$ & \\
\hline
\end{tabular}

Means followed by same letters in a column are not statistically significant by DMRT, ** significant at 0.01 level

Pandey et al. (1994) worked with matured dehulled rice seeds using different level of 2, 4-D in nutrient medium and they concluded that seed response for callusing was the best on $2 \mathrm{mg} / 1$. Other workers like Islam et al. (2004) obtained good number of calli on the MS based medium when 2, 4-D $1 \mathrm{mg} / 1$ was applied. Further they reported that best embryogenic calli were recovered from 2, 4-D supplied media than the media supplemented with phenylacetic acid and other organic supplements. Present study also found that 2, 4-D supplied @ $2.5 \mathrm{mg} /$ 1 was the best for callus induction and subsequent regeneration in contrary to Chen et al. (1991), who reported that regeneration ability in calli obtained from 2, 4-D supplied medium was quite low as compared to that formed on medium supplemented with NAA. The non significant difference observed between medium B and $\mathrm{C}$ (Table 1) reflects that the $\mathrm{AgNO}_{3}$, ethylene inhibitors in vitro, supplied @ $5 \mathrm{mg} / \mathrm{l}$ in B medium had not any affects on callus induction and regeneration, however, it greatly improved the regeneration ability of calli that induced in medium A (Table 2). Although relatively high frequency of callus was observed in this study as compared to the report of other workers (Islam et al., 2004), the overall regeneration was quite low. It was observed that green plant regeneration ability of plated calli depends on the genotypes and the callus induction media. Altogether 11 rice plants were regenerated and are growing in glass house for further study. Among the studied rice genotypes Tilki regenerated maximum number of plants $(27.77 \%)$ followed by Masuli $(20 \%)$ and Jethobudo (11.76\%) only from the calli induced in medium A (Table 2 and Figures. 3,4,5,6,7 and 8). Similar results were reported by other workers in rice using different genotypes and media composition (Islam et al., 2004, Khatun et al., 2003). Moreover, regeneration was almost zero when calli induced in medium A without 10 
mg $\mathrm{AgNO}_{3}$ (data not shown). Therefore, it is speculated that $\mathrm{AgNO}_{3}$ is only compatible with nutrients composition of medium A. Similar positive effect of $\mathrm{AgNO}_{3}$ was reported by Laxmi and Reddy (1997) for indica rice anther culture. The higher rate of callus induction and low rate of regeneration observed in this study might be attributed to relatively higher doses of auxin source used in the callus induction medium. Therefore, exact level of hormone in the callus induction medium requires some degree of compromise between callus induction and regeneration frequency.
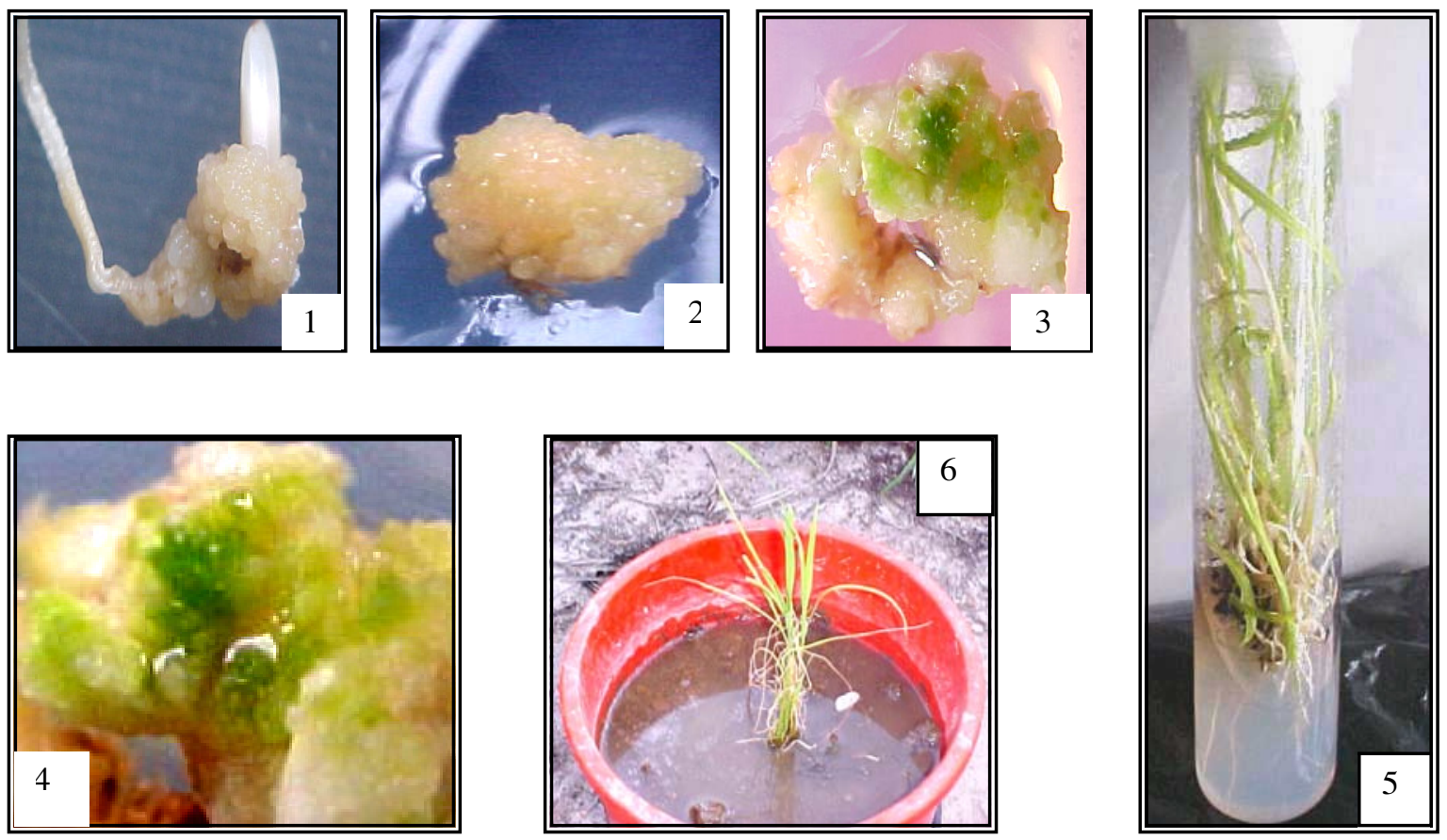

Figures 1. Showing different stages of callus induction and regeneration from matured rice seeds in vitro: 1-2) calli obtained from Masuli., 3) initiation of green chloroplast pigment (arrow) after 4 days of incubation at regeneration medium, 4) calli ready to regenerate (arrows) after 7 days of culture in regeneration medium, 5) fully developed plantlets and 6) successful field transferred of regenerants, genotype Tilki
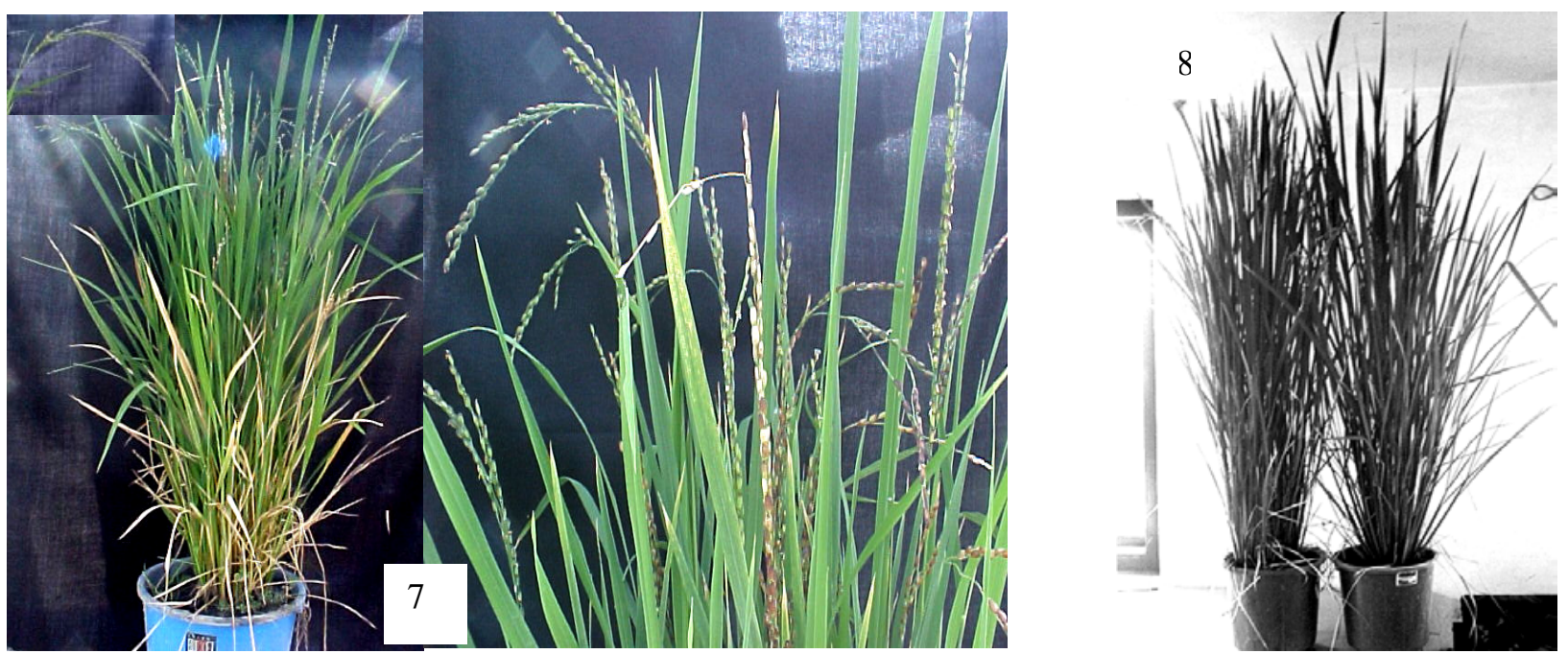

Figures 2. Growing regenerated plant (somaclone) derived from seed calli: 7) regenerated plant from Tilki at milking stage, and 8) showing parent (left) and regenerated plant (right) at flowering stage of Masuli 
Table 2. Effect of genotypes and callus induction media on frequency of green plant regeneration

\begin{tabular}{|c|c|c|c|c|}
\hline Genotypes & $\begin{array}{l}\text { Callus induction } \\
\text { media }\end{array}$ & $\begin{array}{l}\text { No. of calli plated in } \\
\text { regeneration medium }\end{array}$ & $\begin{array}{l}\text { No. of green } \\
\text { plant }\end{array}$ & $\begin{array}{c}\text { Regeneration } \\
(\%)\end{array}$ \\
\hline \multirow[t]{3}{*}{ Jumlimarshi } & A & 20 & 1 & 5 \\
\hline & B & 8 & 0 & 0 \\
\hline & C & 10 & 0 & 0 \\
\hline \multirow[t]{3}{*}{ Tilki } & A & 18 & 5 & 27.77 \\
\hline & B & 15 & 0 & 0 \\
\hline & $\mathrm{C}$ & 12 & 0 & 0 \\
\hline \multirow[t]{3}{*}{ Jethobudo } & A & 17 & 2 & 11.76 \\
\hline & B & 16 & 0 & 0 \\
\hline & C & 13 & 0 & 0 \\
\hline \multirow[t]{3}{*}{ Manshara } & A & 12 & 0 & 0 \\
\hline & B & 17 & 0 & 0 \\
\hline & $\mathrm{C}$ & 11 & 0 & 0 \\
\hline \multirow[t]{3}{*}{ Masuli } & A & 15 & 3 & 20 \\
\hline & B & 18 & 0 & 0 \\
\hline & $\mathrm{C}$ & 10 & 0 & 0 \\
\hline \multirow[t]{3}{*}{ Pahenle } & A & 14 & 0 & 0 \\
\hline & B & 8 & 0 & 0 \\
\hline & $\mathrm{C}$ & 10 & 0 & 0 \\
\hline Total & - & 244 & 11 & - \\
\hline
\end{tabular}

In summary, rice genotypes showed significant divergence for their in vitro response to callus induction. The quality and frequency of callus induction and subsequent plant regeneration, however, ultimately depends on composition of initial callus induction medium. Therefore, selection of better responsive rice genotypes like Tilki, Masuli and Jethobudo and medium designated as A would offer great promise for the induction of higher level of desired somaclones and quality of callus for various means of genetic transformation and other studies for improving this world's staple food crop.

\section{ACKNOWLEDGEMENTS}

We thank NARC for financial supports and B. Dangol for laboratory help.

\section{REFERENCES CITED}

Abe, T. and Y. Futsuhara. 1986. Genotypic variability for callus formation and plant regeneration in rice (Oryza sativa L.). Theor. Appl. Genet. 72:3-10.

Brar, S.D. and G.S. Khush. 1994. Cell and tissue culture for plant improvement. pp.229-278. In: A.S.Basra (ed.), Mechanisms of plant growth and improved productivity: Modern approaches. Marcel Dekkar Inc., New York, USA.

Chen, C.C., H.S. Tsay, and C.R. Huang. 1991. Factors affecting androgenesis in rice (O. sativa L.). p.200. In: Y.P.S. Bajaj (ed.), Biotechnology in Agriculture and Forestry. Vol. 14. Rice. Springer-Verlag, Berlin Heidelberg.

Chu, C.C. 1978. The N6 medium and its applications to anther culture of cereal crops. pp. 45-50 In: Proceedings of the Symposium on Plant Tissue Culture held at Peking, China during 25-30 May. Science Press, China.

Gomez, K.A. and A.A. Gomez. 1984. Statistical procedures for agricultural research. $2^{\text {nd }}$ edition. John Wiley \& Sons, New York. pp. 197-198.

Guo, C.Y. and Z.Y. Cao. 1982. Effect of different genotypes on induction frequency in anther and scutellum culture of maize in vitro. Heredities (China). 4(4):8-10.

Gupta, P.K. 1999. Haploidy in higher plants. In: Cytogenetics. Rastogi Publication, Shivaji Road Meerut, India. pp. 116-119.

Hartke, S. and H. Lorz. 1989. Somatic embryogenesis and plant regeneration from various indica rice (Oryza sativa L.) genotypes. J. Genet. Breed. 43:205-214.

Islam, M.M., S.A. Wahed, and S.A.K.U. Khan. 2004. Studies on callus induction and regeneration from dehulled rice (Oryza sativa L.) seeds. Plant Tissue Cult. 14(2): 155-160. 
Khanna, H.K. and S.K. Raina. 1998. Genotype x culture media interaction effects on regeneration response of three indica rice cultivars. Plant Cell, Tissue and Organ Cult. 52:145-153.

Khatun, M.M., M. H. Ali, and N.V. Desamero. 2003. Effect of genotype and culture media on callus formation and plant regeneration from mature seed scutella culture in rice. Plant Tissue Cult. 13(2):99-107.

Laxmi, G.V. and G.M. Reddy. 1997. Anther culture of indica rice: technical improvements in callus induction and green plant regeneration. J. Genet. Breed. 51:295-301.

Lutts, S., J. Bouharmont, and J.M. Kinet. 1999. Physiological characterization of salt resistance rice (Oryza sativa) somaclones. Aust. J. Bot. 47:835-849.

Lutts, S., J.N. Kinet, and J.Bouharmont. 2001. Somaclonal variation in rice after two successive cycles of mature embryo derived callus culture in presence of $\mathrm{NaCl}$. Biol. Plant. 44(4):489-495.

Murashige, T. and F. Skoog. 1962. A revised medium for rapid growth and bioassays with tobacco tissue cultures. Plant Physiol. 39:375-383.

Niroula, R.K., L.P. Subedi, R.C. Sharma, and M.P. Upadhyay. 2003. Embryo culture for wide hybridization in the genus Oryza:: A simplified technique of hardening improves the field plant establishment In: Second SAS Convention held at Khumaltar during 30 July-1 August, 2003 (in press).

Pandey, S.K., B. Ramesh, and P.K. Gupta. 1994. Study on effect on genotype and culture medium on callus formation and plant regeneration in rice (Oryza sativa L.). Indian J. Genet. 54:293-299.

Qu, R.D. and Y. Chen. 1983. A preliminary research on the function of enhancement of callus induction frequency. Acta Phytophysiol. Sci. 9:375-381.

Raina, S.K. 1989. Tissue culture in rice improvement: status and potential. Adv. Agron. 42: 339-398.

Sathish, P., O.L. Gamborg, and N.W. Nabors. 1995. Rice anther culture: callus initiation and androclonal variation in progeny of regenerated plants. Plant Cell Rep. 14:432-436.

Shen, J.H., M.F. Chen, and Y.Q. Zhang. 1982. Breeding in rice variety improvement. Sci. Agric. Sin. pp.15-19.

Skirvin, R.M. 1978. Natural and induced variation in tissue culture. Euphytica 27(1):241- 266.

Sun, Z.X. and K.L. Zheng. 1990. Somac1onal variation in rice. pp. 288-325. In: Y.P.S Bajaj (ed.), Biotechnology in Agriculture and Forestry, Vol. 11: Somaclonal variation I crop improvement SpringIer-Verlag, Berlin.

Torbert, K.A., H.W. Rines, and D.A. Somers. 1998. Transformation of oat using mature embryo-derived tissue cultues. Crop Sci. 38:226-231.

Tyagi, A.K., J.P. Khurana, P. Khurana, S. Raghuvanshi, A. Gaur, A. Kapur, V. Gupta, D. Kumar, V. Ravi, S. Vij, P. Khurana, and S. Sharma. 2004. Structural and functional analysis of rice genome. J. Genet. 83:79-99.

Wang, M.S., F.J. Zapata, and D.C. De Castro. 1987. Plant regeneration through somatic embryogenesis from mature seed and young inflorescence of wild rice (Oryza perennis Moench). Plant Cell Rep. 6:294-296. 